man was described with failure of medical treatment for recurrent pulmonary emboli. ${ }^{5}$ PTE was successfully performed, with no recurrence of CTEPH at the 7-month follow-up. An 11-year-old boy was reported to have undergone pulmonary thromboendarterectomy (Huiras and colleagues $^{3}$ ), but he died after recurrent PE.

\section{CONCLUSIONS}

PTE is a difficult operation to perform. The procedure was developed and advanced by Jamieson and colleagues. ${ }^{1}$ As experience with the technique has grown, many centers have seen mortality decrease to less than $5 \%$. There are 3 previously reported cases of PTE performed for KTS, but 2 of the patients died after surgery. ${ }^{3-5}$ PTE should be performed only by surgeons who are experienced with the operation. In selected patients, PTE can be an effective and potentially lifesaving curative procedure, and it is an important therapeutic option in patients with CTEPH.

\section{References}

1. Jamieson SW, Kapelanski DP, Sakakibara N, Manecke GR, Thistlethwaite PA, Kerr KM, et al. Pulmonary endarterectomy: experience and lessons learned in 1,500 cases. Ann Thorac Surg. 2003;76:1457-64.

2. Klippel M, Trenaunay P. Du naevus variquex osteohypertrophique. Arch Gen Med (Paris). 1900;3:641-72.

3. Huiras EE, Barnes CJ, Eichenfield LF, Pelech AN, Drolet BA. Pulmonary thromboembolism associated with Klippel-Trenaunay syndrome. Pediatrics. 2005; 116 e596-600.

4. Mikula N Jr, Gupta SM, Miller M, Felder S. Klippel-Trenaunay-Weber syndrome with recurrent pulmonary embolism. Clin Nucl Med. 1991;16:253-5.

5. Walder B, Kapelanski DP, Auger WR, Fedullo PF. Successful pulmonary thromboendarterectomy in a patient with Klippel-Trenaunay syndrome. Chest. 2000; 117:1520-2.

\title{
Successful surgery for atrioesophageal fistula caused by transcatheter ablation of atrial fibrillation
}

\author{
Alexandre Cazavet, MD, ${ }^{\mathrm{a}}$ Fabrice Muscari, MD,${ }^{\mathrm{b}}$ Marie Agnès Marachet, $\mathrm{MD},{ }^{\mathrm{c}}$ and \\ Bertrand Léobon, MD, PhD, ${ }^{a}$ Toulouse, France
}

Catheter ablation (CA) is an effective and safe technique to treat atrial fibrillation; however, it can cause rare but lethal complications. ${ }^{1}$ Atrioesophageal fistula (AEF) caused by diffusion of the ablative energy through the left atrial wall to the esophagus (because of the absence of pericardium) is lethal if not treated surgically.

\section{CLINICAL SUMMARY}

A 35-year-old man had a 3-year history of atrial fibrillation that had been permanent for the last 2 years. Amiodarone had proven ineffective, and an electrical cardioversion failed. Echocardiography showed the left side of his heart (left ventricular ejection fraction, $60 \%$ ) to be preserved with a left atrial diameter of $27 \mathrm{~mm}$. CA performed at another institution was uneventful, and the patient was discharged the next day in sinus rhythm.

\footnotetext{
From the Departments of Cardiovascular Surgery B,${ }^{\mathrm{a}}$ Digestive Surgery, ${ }^{\mathrm{b}}$ and Radiology, ${ }^{\mathrm{c}}$ University Hospital of Rangueil, ${ }^{\mathrm{b}}$ Toulouse, France.

Disclosures: None.

Received for publication Feb 10, 2010; accepted for publication Feb 20, 2010; available ahead of print April 12, 2010.

Address for reprints: Bertrand Léobon, MD, PhD, Department of Cardiovascular Surgery B (Pr. Fournial), University Hospital of Rangueil, 1 avenue Jean Poulhès, TSA 30030, 31059 Toulouse Cedex 9, France (E-mail: leobon.b@chu-toulouse.fr).

J Thorac Cardiovasc Surg 2010;140:e43-5

$0022-5223 / \$ 36.00$

Copyright (c) 2010 by The American Association for Thoracic Surgery

doi:10.1016/j.jtcvs.2010.02.032
}

Thirty-eight days later, the patient had fever, chest pain, and vomiting and was urgently admitted to a peripheral hospital, where he presented a left hemiplegia and convulsive crisis. There was no early lesion observed on cerebral computed tomography (CT) scan. Blood cultures were positive for streptococcus salivarius, transthoracic echocardiography showed no evidence of endocarditis, and lumbar puncture results were unremarkable. A specific antibiotic therapy was initiated, and the patient was transferred to the University Hospital of Rangueil. Cerebral magnetic resonance imaging showed widespread ischemic changes consistent with multiple emboli, and CT scan showed cerebral, splenic, and renal emboli associated with the presence of air within the mediastinum and left atrium, suggesting an AEF (Figure 1).

Because of the patient's poor condition, a silicone-covered stent was initially placed in the esophagus under radioscopy to seal off the AEF, but the stent migrated into the stomach a few hours later.

Surgery was performed via a left thoracotomy because of a left pleural effusion. The left femoral vessels were accessible, and a cardiopulmonary bypass was on standby. After careful dissection, the AEF was identified and the esophagus was separated from the left atrial wall. A preventive suture was done on the atrial wall despite the absence of perforation. The esophageal perforation (Figure 2, $B$ ) was closed using adsorbable monofilament sutures. A pediculated autologous pericardial patch was then placed between the 


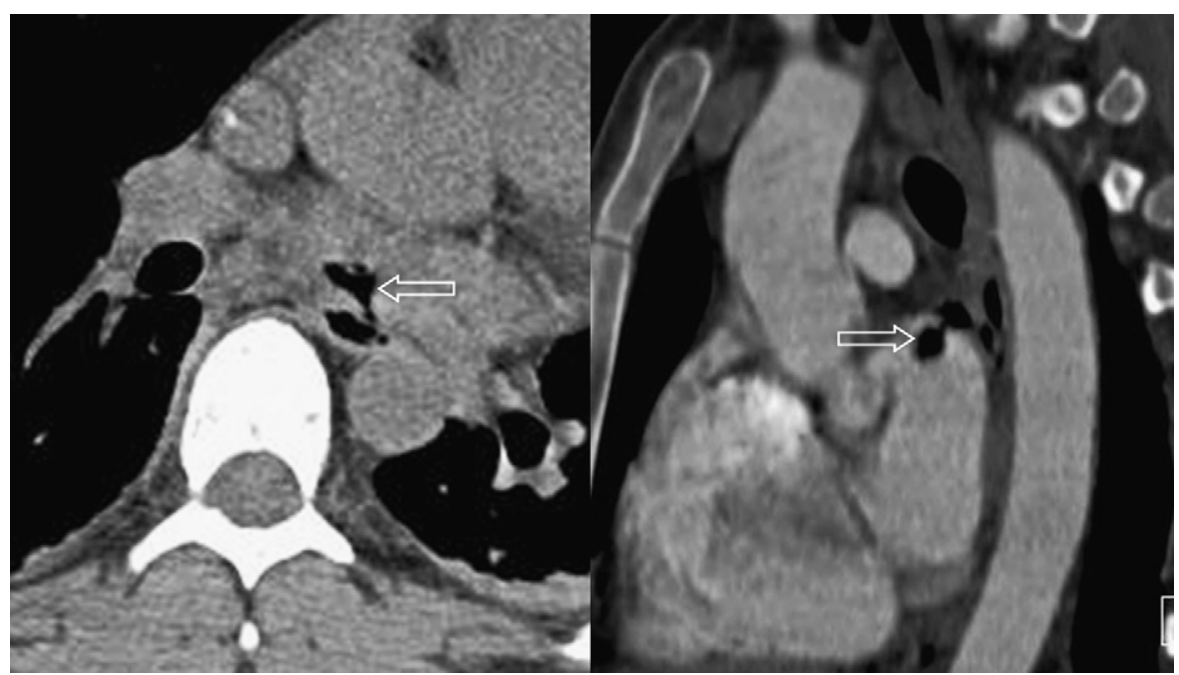

FIGURE 1. CT scan showing the presence of air within the mediastinum and left atrium (white arrows).

2 sutures (Figure 2, A). A mediastinal drain was placed adjacent to the esophagus associated with a left pleural drain. Two nasogastric tubes were placed, one above the suture and one in the stomach. The patient had parenteral feeding associated with intravenous antibiotic therapy. After

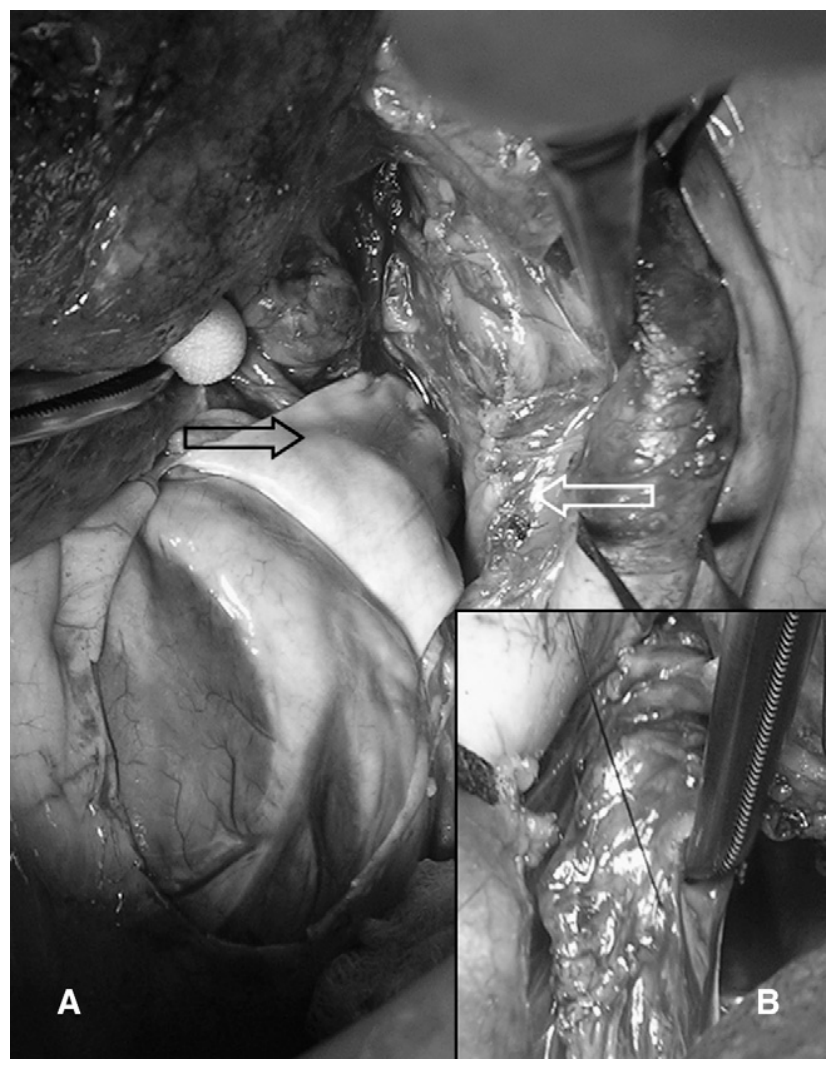

FIGURE 2. Intraoperative views showing the esophageal perforation (B) and the interposition of a pediculated pericardial flap (A) (black arrow) between the left atrium and the esophageal sutures (white arrow). a water-soluble contrast CT scan that showed no esophageal leakage, drains were progressively removed and oral nutrition was reintroduced progressively 3 weeks after surgery. The patient was discharged after 5 weeks.

One month later, a gastroscopy was performed to assess esophageal healing and remove the esophageal stent. Nine months later, the patient was in sinus rhythm and doing well despite his sequela left lower limb hemiparesis.

\section{DISCUSSION}

AEF is a serious complication of CA for atrial fibrillation. A recent multicenter retrospective study reported 32 deaths after 45,115 procedures $(0.098 \%)$. AEF was the second most frequent cause of death $(\mathrm{n}=7 ; 15,6 \%)$, and overall mortality of AEF was $71.4 \%(n=5 / 7) .{ }^{1}$

The clinical features consist of nonspecific symptoms, such as fever, dysphagia, chest pain, or hematemesis, beginning 3 to 38 days after the procedure. Subsequently, endocarditis or pericarditis and finally multiple air emboli occur. One hypothesis about the air emboli is the capability of the esophagus to develop pressures 10 times greater than intra-atrial pressure. ${ }^{2}$ Causes of death are cerebral embolism, massive gastrointestinal bleeding, and septic shock.

Chest CT scan is the most useful diagnostic method and specifically shows air bubbles or a fistulous tract. Transthoracic echocardiography is useful to assess the absence of endocarditis lesion. Transesophageal echocardiography and gastroesophageal endoscopy are contraindicated considering the risk of air embolism. ${ }^{3}$

\section{CONCLUSIONS}

Despite the report of one case of treatment with a temporary esophageal covered stent, ${ }^{4}$ this solution failed in our case. Conventional treatment consists of urgent surgical intervention, because this is vital for all patients. ${ }^{3,5} \mathrm{~A}$ 
cardiopulmonary bypass has to be ready, even if it should be reserved for salvage, because of recent neurologic lesions that are often associated. We preferred an off-pump strategy via a lateral thoracotomy, rather than a sternotomy, for an elective intracardiac repair. The choice of the left side for the approach was based on left pleural effusion draining the mediastinal infection, but a right access to the esophagus is also feasible. The esophageal repair or esophagectomy is chosen according to the local severity of necrosis and mediastinitis. A pericardial flap was easy and efficient to separate the atrial and esophageal sutures, correcting the natural pericardial defect that caused AEF after CA.

\section{References}

1. Cappato R, Calkins H, Chen SA, Davies W, Iesaka Y, Kalman J, et al. Prevalence and causes of fatal outcome in catheter ablation of atrial fibrillation. $J$ Am Coll Cardiol. 2009;53:1798-803.

2. Grande L, Lacima G, Ros E, Pera M, Ascaso C, Visa J, et al. Deterioration of esophageal motility with age: a manometric study of 79 healthy subjects. Am J Gastroenterol. 1999; $94: 1795-801$.

3. Doll N, Borger MA, Fabricius A, Stephan S, Gummert J, Mohr FW, et al. Esophageal perforation during left atrial radiofrequency ablation: is the risk too high? J Thorac Cardiovasc Surg. 2003;125:836-42.

4. Bunch TJ, Nelson J, Foley T, Allison S, Crandall BG, Osborn JS, et al. Temporary esophageal stenting allows healing of esophageal perforations following atrial fibrillation ablation procedures. J Cardiovasc Electrophysiol. 2006;17:435-9.

5. Pappone C, Oral H, Santinelli V, Vicedomini G, Lang CC, Manguso F, et al. Atrioesophageal fistula as a complication of percutaneous transcatheter ablation of atrial fibrillation. Circulation. 2004;109:2724-6.

\title{
Lower graft patency after off-pump than on-pump coronary artery bypass grafting: An updated meta-analysis of randomized trials
}

\author{
Hisato Takagi, MD, PhD, Masafumi Matsui, MD, and Takuya Umemoto, MD, PhD, Shizuoka, Japan
}

Our previous meta-analysis of randomized trials demonstrated a significant increase in overall graft occlusion, especially in saphenous vein graft occlusion, in off-pump coronary artery bypass grafting (CABG) compared with on-pump CABG. ${ }^{1}$ Since we conducted the meta-analysis, graft patency in several randomized trials has been reported. The likelihood of graft occlusion was no different between off-pump and on-pump CABG groups in a study by Angelini and associates, ${ }^{2}$ whereas Shroyer and collaborators ${ }^{3}$ revealed that the overall rate of graft patency was lower in the off-pump group than in the on-pump group. We performed an updated meta-analysis of graft patency after offpump versus on-pump CABG from randomized trials.

\section{CLINICAL SUMMARY}

All prospective randomized controlled trials that compared graft patency of 3 or more months after off-pump versus on-pump CABG were identified using a 2-level search strategy. First, a public domain database (MEDLINE) was

\footnotetext{
From the Department of Cardiovascular Surgery, Shizuoka Medical Center, Shizuoka, Japan.

Disclosures: None.

Received for publication Nov 9, 2009; accepted for publication Nov 22, 2009; available ahead of print Jan 14, 2010.

Address for reprints: Hisato Takagi, MD, PhD, Department of Cardiovascular Surgery, Shizuoka Medical Center, 762-1 Nagasawa, Shimizu-cho, Sunto-gun, Shizuoka 411-8611, Japan (E-mail: kfgth973@ybb.ne.jp).

J Thorac Cardiovasc Surg 2010;140:e45-7

$0022-5223 / \$ 36.00$

Copyright $(C) 2010$ by The American Association for Thoracic Surgery

doi:10.1016/j.jtcvs.2009.11.045
}

searched with a Web-based search engine (PubMed). Second, relevant studies were identified through a manual search of secondary sources, including references of initially identified articles and a search of reviews and commentaries. The MEDLINE database was searched from January 1966 to October 2009. Exploding keywords included "off-pump," "off pump," “opcab," “patency," and "randomized trial." Studies considered for inclusion met the following criteria: The design was a prospective randomized controlled clinical trial; patients were randomly assigned to off-pump or on-pump CABG; and main outcomes included graft patency of 3 or more months. Data regarding detailed inclusion criteria; duration of follow-up; and internal thoracic artery, saphenous vein, and overall graft patency were abstracted from each individual study. For each study, data regarding patency in both the off-pump and on-pump $\mathrm{CABG}$ groups were used to generate risk ratios (RRs) for graft occlusion $(<1$, favors off-pump CABG; $>1$, favors on-pump CABG) and 95\% confidence intervals (CIs). Study-specific estimates were combined with inverseweighted averages of logarithmic RRs in both fixed- and random-effects models. Between-study heterogeneity was analyzed by means of standard chi-square tests. Where no significant statistical heterogeneity was identified, the fixed-effects estimate was used preferentially as the summary measure. Sensitivity analyses were performed to assess the contribution of each study to the pooled estimate by excluding individual trials one at a time and recalculating the pooled RR estimates for the remaining studies. To assess the impact of differential length of follow-up on the pooled 